\title{
CONFLICTO SOCIOAMBIENTAL EN EL PROCESO DE MANEJO DE LOS RESIDUOS SÓLIDOS EN LA PROVINCIA DE HUANCAYO. CASO "LASTAY"
}

\author{
Marisol Condori Apaza* y Gustavo Reyna Arauco* \\ Facultad de Sociología de la Universidad Nacional del Centro del Perú \\ RESUMEN
}

Durante los últimos años, el Perú viene atravesando por diversos conflictos socios ambientales que ocasionan no sólo pérdidas materiales, sino pérdidas humanas que son irrecuperables. En dichos conflictos "están en juego más que las oportunidades de crecimiento económico, la suerte del medio ambiente local, la calidad de vida de la población y la continuidad de las economías territoriales y sistemas de vida tradicional (...) las concepciones del mundo, de la naturaleza y de la forma en que los seres humanos se relacionan y organizan entre si" 49 . Las ciudades que vienen creciendo demográfica y territorialmente, ingresan a un proceso de "modernidad" que los empuja al consumismo de bienes y servicios. Precisamente ese consumismo acelerado crea grandes cantidades de residuos sólidos, cuya disposición final generará conflictos socio ambientales, ya que, las personas tenemos derecho a habitar un ambiente saludable, libre de agentes patógenos o contaminantes; y para acceder a ello, según algunos entrevistados, los residuos sólidos deben estar alejados de lugares habitables y de terrenos agrícolas y ganaderos. Huancayo no está ajeno a esta problemática, porque entre los principales distritos como son: Huancayo, El Tambo y Chilca, la ciudad metropolitana de Huancayo genera un total de 258 toneladas diarias de residuos sólidos y, para su confinamiento final, las autoridades plantean propuestas, pretenden implementar proyectos, que más que un acuerdo entre autoridades, sociedad civil y población, genera consigo conflictos socio ambientales. Tal es el caso acontecido el año 2008 en el anexo de Lastay ${ }^{50}$, lugar donde se pretendió construir una planta de tratamiento de residuos sólidos para dar solución al problema de disposición final de los mismos. Pero, más que solución lo que se generó fue un enfrentamiento, ya que los pueblos (Lastay y anexos aledaños) organizados en sociedad civil encabezado por el Alcalde de Concepción, Oscar Berríos Fuentes, iniciaron una ofensiva colectiva que mantuvo enfrentadas a las provincias de Huancayo y Concepción, lo cual ocasionó pérdidas humanas y materiales. Finalmente, el proyecto se frustró, ya que no se logró obtener la licencia social. Este hecho muestra una clara oposición por gran parte de la población hacia la construcción de plantas de tratamiento de residuos sólidos u otros proyectos similares cerca a lugares habitables y/o terrenos agrícolas, y es más, ha generado crisis de gobernabilidad local y una imagen negativa del burgomaestre en turno a quien la prensa hablada y escrita ha calificado con adjetivos de pérdida de principio de autoridad y falta de capacidad y eficiencia en la gestión local respecto a la solución de los problemas de la ciudad.

Palabras clave: Conflictos socio ambientales, residuos sólidos, salud ambiental, participación ciudadana, gobernabilidad.

\section{SOCIOAMBIENTAL CONFLICT IN THE PROCESS OF SOLID WASTE MANAGEMENT IN THE PROVINCE OF}

\section{HUANCAYO. CASE "LASTAY"@}

\begin{abstract}
In recent years, Peru is going through various socio-environmental conflicts that cause not only material losses, but loss of life which are not recoverable. In those conflicts are at stake more than economic growth opportunities, the fate of the local environment, population life quality and continuity of regional economies and traditional ways of life (...) the conceptions of the world, nature and how humans interact and organize among themselves. The cities are growing demographic and territorial, they enter to a process of "modernity" that pushes the consumption of goods and services. Precisely that accelerated consumerism creates large amounts of solid waste disposal which will generate socio-environmental conflicts, since people have a right to live in a healthy environment, free of pathogens or contaminants and to access it, according to some interviewees, Solid waste must be removed from living quarters and agricultural land and livestock. Huancayo is no stranger

\footnotetext{
•betreyna23@hotmail.com

*marisol_c_a@hotmail.com

${ }^{49}$ VINYAMATA C. E. (1999) Manual de Prevención y Resolución de Conflictos. Conciliación, Mediación, Negociación. Editorial Ariel S.A., Barcelona, Febrero. Pág. 67-68.

${ }^{50} \mathrm{El}$ anexo de Lastay pertenece al distrito de Quichuay, provincia de Huancayo, departamento de Junín.

${ }^{\circ}$ Este trabajo de investigación fue recibido el 20/03/09, retornado para su revisión 26/10/09 y aprobado para su publicación 08/10
} 
to this problem, because among the major districts such as: Huancayo, El Tambo and Chilca, the metropolitan city of Huancayo generates a total of 258 tons per day of solid waste for final confinement, the authorities proposed plants seek to implement projects, more than an agreement between authorities, civil society and population, it generates socioenvironmental conflicts. Such is the case occurred in 2008 in the annex of Lastay, where they tried to construct a waste solids treatment plant to solve the problem of disposal. But more than a solution what was generated was fought because the people (and annexes surrounding Lastay) organized civil society led by the Mayor of Concepcion, Oscar Berrios Fuentes, began an offensive collective remained facing the provinces of Huancayo and Concepcion, which caused human and material losses. Finally, the project was stopped because it was not possible to obtain the social license. This shows a clear opposition from most of the population towards the construction of treatment plants, solid waste or other similar projects near living quarters and / or agricultural land, and moreover, has generated local governance crisis and a negative of he mayor who in turn spoken and written press has described with adjectives of loss of principle of authority and lack of capacity and efficiency of local management with respect to solving the problems of the city.

Key words: socio-environmental conflicts, solid waste, environmental health, public participation, governance.

\section{INTRODUCCIÓN}

La investigación titulada "Conflictos socio ambientales en el proceso de manejo de los residuos sólidos en la provincia de Huancayo. Caso Lastay"^, aborda sobre una problemática que viene aconteciendo en sociedades cuyo consumo se incrementa cada vez más y por ende los residuos sólidos que esta crea van en aumento en nuestra sociedad mientras que para unos "la basura" significa "ganancias económicas", para otros significa "contaminación, pobreza, enfermedad y muerte". La mentalidad que los individuos tienen sobre los residuos sólidos es diversa; existen enfrentadas cosmovisiones respecto al medio ambiente y a la vida. Desde una mirada empresarial, el medio ambiente es percibido como un recurso económico, pero desde otras ópticas, el medio ambiente es un espacio que se debe respetar, valorar y mantener limpio, fuera de agentes contaminantes, que puedan hacerla inhabitable $o$ insalubre.

En tal sentido, la presente investigación tiene como objetivos 1) Conocer los factores causantes del conflicto socio ambiental en el anexo de Lastay, 2) Conocer los impactos ocasionados por el conflicto y 3) Describir el proceso de negociación del conflicto. Las hipótesis que se plantearpon son: 1) El conflicto socio ambiental entorno a la construcción de una planta de tratamiento de residuos sólidos en el anexo de Lastay tuvo causantes multifactoriales, entre ellos ambientales, económicos, socioculturales, políticos y legales. 2) Los impactos ocasionados por el conflicto fueron daños materiales, pérdidas humanas y conflictos internos. 3) En el proceso de negociación del conflicto en torno a la construcción de la

\footnotetext{
- La presente investigación también contó con la participación y aportes del M.Sc. Filoter Tello Yance, docente principal de la Facultad de Sociología de la UNCP.
}

planta de tratamiento de residuos sólidos en Lastay, se recurrió a la negociación asistida, considerando los métodos de mediación y arbitraje.

Para el sustento teórico, se recurrió a la teoría del conflicto social, con teóricos como C. Marx, E. Durkheim, M. Weber, G.H. Mead, H. Arent, W. Mills, entre otros.

Para una mejor comprensión, la investigación se dividió en temáticas como: Residuos sólidos, un problema que aun no se ha solucionado; factores causantes del conflicto; impactos del conflicto y la negociación.

Se espera que la presente investigación aporte, desde un enfoque sociológico, al estudio de los conflictos socio ambientales en nuestra región y país.

\section{MATERIALES Y MÉTODOS}

El trabajo de investigación se realizó en la comunidad campesina de Lastay y anexo del mismo nombre, ubicado en el distrito de Quichuay, provincia de Huancayo. Los materiales utilizados al momento de la aplicación de los instrumentos en el proceso de la recopilación de la información fueron: la grabadora digital y la cámara fotográfica. Por la naturaleza de la investigación se recurrió al enfoque metodológico cualitativo, considerando las técnicas de la entrevista y los testimonios. (Debemos señalar que los entrevistados desean mantener su anonimato, por lo que las entrevistas sólo se enumeran) Así mismo se recurrió a la técnica del análisis documental.

\section{PRESENTACIÓN Y DISCUSIÓN DE RESULTADOS}

En el presente acápite, se presentan, discuten y analizan los principales resultados hallados en el proceso de la investigación. Pero antes es necesario dejar en claro que, para la presente investigación el conflicto es entendido 
como una "circunstancia en el cual dos ó más -actores sociales- perciben tener intereses mutuamente incompatibles, ya sea total o parcial contrapuestos y excluyentes, generando un contexto confrontativo de permanente oposición." ${ }^{11}$

\section{Residuos sólidos, un problema que aún no se ha} solucionado

En la ciudad metropolitana de Huancayo, al igual que otras grandes y medianas ciudades del país, el crecimiento demográfico que viene dándose también trae consigo mayor consumismo y por ende mayor cantidad de residuos sólidos por día, tal como se visualiza en el cuadro $\mathrm{N}^{0}$ 1. Los gobiernos locales no se encuentran en la capacidad de solucionar aún este problema que viene creciendo cada vez más. A pesar de que se cuenta con un presupuesto y un significativo número de trabajadores para esta labor, las calles continúan sucias, los residuos muchas veces son arrojados a los ríos (Mantaro y otros), a los botaderos informales, afectado sensiblemente la salud física y psicológica de un gran sector de la población.

\section{Cuadro $\mathrm{N}^{0} 1$}

Cantidad de residuos sólidos y número de trabajadores

\begin{tabular}{lcc}
\hline DISTRITOS & $\begin{array}{c}\text { CANTIDAD DE } \\
\text { RESIDUOS SÓLIDOS } \\
\text { (TM/DIA) }\end{array}$ & $\begin{array}{c}\text { NÚMERO DE } \\
\text { TRABAJADORES }\end{array}$ \\
\hline HUANCAYO & 110 & 129 \\
EL TAMBO & 98 & 100 \\
CHILCA & 50 & 43 \\
TOTAL & 258 & 272 \\
\hline
\end{tabular}

Fuente: Archivo municipalidades de Huancayo, El Tambo y Chilca 2008.

\section{El conflicto y sus factores causantes}

Las teorías del conflicto se derivan de los trabajos de Karl Marx, quien vio en la lucha de clases la clave de la historia humana y principal fuente de cambio. Actualmente se vincula a Charles Wright Mills y otros sociólogos quienes además de la lucha de clases, analizan otros tipos de conflictos entre productores y consumidores, entre jóvenes y adultos, hombres y mujeres; diversos grupos raciales y étnicos, ${ }^{52}$ como también los conflictos en torno al medio ambiente y los recursos naturales.

Los conflictos sociales en nuestro país se tornan cada vez más violentos debido a que algunos gobiernos, ya

51 Vásquez, R. W. (S/F) Manual de medios alternativos de resolución de conflictos. S/E. Pg. 2.

${ }^{52}$ Ver: http://es.geocities.com/angelcontrerasna/organizacion/foro010.htm sea central, regional o local 0 , empresas privadas consideran proyectos para ser ejecutados en una zona, pero no consideran los puntos de vista de los pobladores que la habitan, ya que éstos se ven amenazados, no sólo como individuos, sino que también ven amenazados su calidad de vida respecto a un ambiente saludable donde habitar, sus actividades económicas, sus formas de vida, entre otros.

En tal sentido, las causas del conflicto socio ambiental acontecido en el anexo de Lastay, son múltiples y complejas. Dicho conflicto se tornó inmanejable precisamente porque no se consideraron adecuadamente sus aspectos fundamentales, lo cual agudizó el mismo hasta tornarlo violento. De acuerdo con los informantes, los factores causantes de este conflicto son: ambientales, económicos, socioculturales, legales y políticos.

\subsection{Factores ambientales}

Cuando hablamos del factor ambiental, nos referimos específicamente a la calidad ambiental, factor que los pobladores del anexo de Lastay y aledaños vieron afectado. La calidad ambiental considera tres elementos fundamentales, como son salud ambiental, salud de las personas e integridad de los ecosistemas. Veamos cómo estos elementos de la calidad ambiental se vieron amenazados con la propuesta de construcción de la planta de tratamiento de residuos sólidos.

\subsubsection{Salud Ambiental y salud de las personas}

Se entiende por salud ambiental cuando “...un ambiente se considerará sano y es capaz de cumplir su función tanto en condiciones normales, como cuando es perturbado por alteraciones externas, manteniendo una cierta capacidad de autorecuperación" ${ }^{53}$. Si consideramos a la salud de las personas en relación con el medio ambiente "...un lugar tendría buena calidad ambiental (...) si cubre adecuadamente las necesidades básicas, de alimentación (productos sanos) aire y agua (limpios), si no hubiera contaminantes, ruidos molestos, etc." 54

Los pobladores de Lastay y aledaños consideran que si la mencionada planta de

\footnotetext{
53 GARMENDIA, S. A., SALVADOR A. A. y otros (2006) Evaluación de impacto ambiental, Pearson Prentice Hall, Madrid, España. Pg. 5.

54 lbid. Pg. 6.
} 
tratamiento se construía en el lugar proyectado por la Municipalidad Provincial de Huancayo y la Empresa DIESTRA, la salud ambiental y de las personas se vería perjudicada enormemente, tal como lo manifiestan a continuación:

"En Lastay no se iba construir una planta de tratamiento, sino un botadero y como tal iba generar un olor insoportable, siendo un foco de contaminación del aire, pudo haber generado enfermedades no previstas, por eso nos hemos resistido a esa construcción, organizándonos. Es por esa razón que acudimos a la invasión y logramos que se vayan los trabajadores y de este modo nos dejen libres de todo malestar a la población afectada." 55

"La planta de tratamiento que intenta construir la Municipalidad de Huancayo es una planta gatuna, porque realizará lo que hace el gato, enterrar la basura, colocarán una capa de basura en hoyos de 30 metros de profundidad, compactado; luego una capa de tierra de 20 a 30 centímetros, que le llaman geomembrana $y$ asi sucesivamente" 56

"La planta de tratamiento significaría un perjuicio para la salud de los comuneros, de nuestros animales y de los cultivos. Nosotros nos dedicamos a la agricultura y con ese proyecto, nos veríamos perjudicados"57

\subsubsection{Integridad de los ecosistemas}

Un lugar mantiene una calidad ambiental en cuanto hay la integridad de los ecosistemas y existe "...la composición de especies, la diversidad y los ciclos de materia y flujos de energía que se producen y mantienen una estructura equilibrada" 58 . En el caso que estudiamos, ante la posible construcción de referida planta de tratamiento de residuos sólidos dentro del territorio y ecosistema de Lastay, la población de este lugar, que tiene una cosmovisión cultural andina de naturaleza y del medio ambiente diferente a la del mundo occidental y los impulsores del proyecto, se vio perturbada por la idea de que referida planta afectaría la integridad de sus ecosistemas: ríos, tierras, flora, auna, entre otros elementos que lo conforman. Al respecto los pobladores afectados muestran su preocupación de la siguiente manera:

"Cercano a Lastay discurre el río Achamayo, que sirve para irrigar la zona agrícola de la zona; todas la quebradas confluyen en este río y por gravedad los 103 metros cúbicos por día de lixiviados que se formarán, irán a parar a su lecho, contaminándolo e inutilizando sus aguas para la irrigación." 59

"El Proyecto asegura, que en esta zona no hay agua freática -pero se equivoca, ya que- si existe agua freática y está a sólo 3 a metros de profundidad; es suficiente que se filtre un centímetro cúbico del lixiviado tóxico para que contamine toda la capa freática." 60

"En esta zona nacen los puquiales de agua que consume la población del distrito de San Jerónimo, que la planta de enterramiento de la basura los contaminará." 61

\subsection{Factores económicos}

\footnotetext{
${ }^{58}$ GARMENDIA, S. A., SALVADOR A. A. y otros. Op. Cit. Pg. 5.

${ }^{59}$ Entrevista $\mathrm{N}^{\circ} 5$

${ }^{60}$ Entrevista $\mathrm{N}^{\circ} 6$

${ }^{61}$ Entrevista $\mathrm{N}^{\circ} 7$
}

\footnotetext{
${ }^{55}$ Entrevista $\mathrm{N}^{\circ} 2$.

${ }^{56}$ (Proyecto págs: 9-14-15-30)

${ }^{57}$ Entrevista ${ }^{\circ} 1$.
} 
El factor económico, es otro elemento fundamental que consideran los pobladores de Lastay y aledaños, ya que, con la construcción de la planta de tratamiento de residuos sólidos veían afectadas sus actividades económicas como la agricultura y ganadería, además del turismo, actividad que tienen pensado aprovechar para obtener beneficios económicos. Respecto a sus actividades agrícolas y ganaderas, los entrevistados manifiestan que:

"Lastay no es una zona eriaza; este lugar es una zona agrícola ganadera, es el Valle Azul, sirve como proveedor de productos a Huancayo y zona de influencia $y$ servirá para la expansión urbana de los pueblos vecinos." ${ }^{2}$

Por otro lado, considerando que el turismo es una actividad que puede aportar al desarrollo de una zona, los pobladores, se oponen a la construcción de la planta de tratamiento en mención, ya que se identifican más que con Huancayo, con Concepción, por la cercanía e identidad común; así, con dicha construcción, al perjudicar a Lastay, perjudicarían también a Concepción y otros distritos y poblados, tal como a continuación lo manifiestan:

"Concepción tiene tres zonas turísticas: Piedra Parada, la Cruz de la Integración y el Museo de Sitio de Lastay. Piedra Parada ha costado más de 2 millones de soles, el Museo de Sitio de Lastay está a menos de 500 metros, la Cruz de la Integración a menos de 300 metros y las ruinas de Unishcoto también están cercanas $y$, son lugares de interés turístico."63

"Concepción ha planificado la zona de Lastay e inmediaciones como zona ecológica y principal destino turístico de la Región de Junín." 64

"Se ha diseñado un circuito
turístico: $\begin{array}{r}\text { Huancayo, San } \\ \text { Jerónimo, Lastay, Quichuay, }\end{array}$

Ingenio, Casacancha, Colpar y
Quilcas."65

"Concepción ha invertido para atraer al turista más de dos millones y medio, para despegar su desarrollo. Al construir la planta de tratamiento el turista será ahuyentado, inutilizado esta inversión y frenará el desarrollo de Concepción y sus inmediaciones." 66

\begin{abstract}
Al respecto, si los pobladores de Lastay y aledaños, quieren mantener equilibrados sus ecosistemas la pregunta es: ¿ si el turismo no afectaría a la integridad de los mismos?, ya que "a lo largo del tiempo la relación entre las actividades del hombre y el ambiente no ha sido armónica, y el turismo a pesar de encontrar en este sistema uno de sus más claros atractivos, tampoco se mantuvo al margen en la generación de problemas ambientales" 67 . En tal sentido, la recomendación que se les haría, es que si apuestan por esta actividad consideren la sostenibilidad ambiental, la cual implica "la conservación y el respeto de los recursos y valores naturales que son la base de la propia actividad turística, y cuya existencia ha de ser garantizada para el futuro, para el propio sostenimiento de la actividad y para asegurar el disfrute del medio por parte de las generaciones futuras. ${ }^{68}$
\end{abstract}

\subsection{Factores socioculturales}

Desde el punto de vista de Emilio Durkheim, el conflicto es un tipo de hecho o fenómeno que más que ser exclusivo de la naturaleza humana, es un hecho social que obedece a lo que tiene de externo, coercitivo e independiente ${ }^{69}$. Entonces debemos considerar al conflicto como un hecho social, en el cual están involucrados diversos actores sociales ${ }^{70}$, quienes muchas veces valiéndose de su poder, económico, político y/o social, vulneran los derechos de otros 0 , simplemente no respetan las leyes y normas sociales. Tal situación se presentó

\footnotetext{
${ }^{65}$ Entrevista $\mathrm{N}^{0} 10$

${ }^{66}$ Entrevista $\mathrm{N}^{0} 11$

${ }^{67}$ Ver:

http://www.naya.org.ar/turismo/congreso2003/ponencias/Aldo_Ramos2.

htm

${ }^{68} \mathrm{lbid}$.

${ }^{69}$ Durkheim E. (1895) "Las reglas del método sociológico"

${ }^{70}$ Los actores sociales se clasifican en: individuos, organizaciones sociales e instituciones.
} 
en Lastay, ya que se intentó construir la planta de tratamiento de residuos sólidos, sin considerar la licencia social, requisito indispensable para la implementación de cualquier proyecto. Para lograr la licencia social, se debe considerar la información responsable, sensibilización, formas de vida de las poblaciones, la cosmovisión sociocultural de las mismas, patrones culturales y sistema cultural, el diálogo, respeto y tolerancia, aspectos que no estuvieron presentes en este proceso, sino, lo que quiso primar fue la imposición por parte del gobierno local de Huancayo, "...lo que realmente ocurre es que los grupos dominantes coaccionan 0 presionan al resto de la población a la sumisión y a la conformidad. En otras palabras, el orden social es mantenido no por el consenso general sino por la fuerza; la amenaza de la fuerza u otras formas sutiles de dominación. Por lo tanto, al preguntarse respecto a quiénes se benefician de tales "acuerdos", responden que aquellos que detentan el poder político y económico." ${ }^{\text {"P }}$ Pero, algunos grupos sociales se revelan a la supuesta autoridad que tienen los gobernantes, ya que van en contra de sus derechos e intereses.

\subsubsection{Desinformación, incertidumbre, falta de diálogo y consideración}

Durante el proceso conflictivo, en Lastay y poblaciones aledañas, reinó la incertidumbre, desinformación y confusión, ya que la población no sabía a ciencia cierta si el proyecto consistía en una planta de tratamiento de residuos sólidos, un relleno sanitario o un botadero. Lamentablemente las instituciones que tienen como objetivo ejecutar proyectos no están realizando las actividades de sensibilización social previas que ésta requiere para su ejecución.

"A nosotros no nos han informado en realidad sobre el proyecto. Algunos decian que sería una planta de tratamiento, otros creían que iban a tapar la basura con un relleno y otros pensaban que se iba a botar la basura. Dicen que han informado, pero esos salen a favor del alcalde y de DIESTRA porque le han ofrecido un dinero. Se supone que la información es para toda la población, no para unos cuantos, porque los interesados somos todos. Ellos

\footnotetext{
${ }^{71}$ Ver: http://es.geocities.com/angelcontrerasna/organizacion/foro010.htm
}

\begin{abstract}
piensan que porque somos personas del campo no sabemos pensar o nos vamos a dejar convencer fácilmente, pero se equivocaron, porque los pobladores de estas zonas, sabemos nuestros derechos y no nos vamos a dejar pisotear por esos que quieren contaminar nuestro ambiente, para eso quieren dividirnos a la población, pero solo unos cuantos se dejan convencer, la mayoría luchamos por nuestra tierra"72.
\end{abstract}

Por otro lado, la población se vio afectada en cuanto a respeto, consideración y falta de diálogo por parte de las autoridades de la provincia de Huancayo, ya que consideran que el alcalde es "un tipo petulante, que no sabe escuchar"

"Las autoridades locales de Huancayo no nos escucharon el clamor de miles de personas que moramos en el entorno de la planta de tratamiento, ellos se imaginaron que unos cuantos revoltosos o algunos políticos de oposición son los que están poniendo determinados obstáculos. Pero esta idea fue equivocada de parte del Alcalde de la Municipalidad de Huancayo y ahí vemos los resultados por no existir el diálogo y solución armoniosa."73

\subsection{2 "No quisieron respetar nuestra forma de pensar"}

La sociedad y sus actores sociales no son homogéneos respecto a su cosmovisión, formas de vida y patrones culturales existentes. Considerando la construcción de la planta de tratamiento de residuos sólidos, existieron dos puntos de vista contrapuestos. Mientras que el alcalde de la Municipalidad Provincial de Huancayo valoró más los intereses económicos y contratos firmados con la empresa DIESTRA, la población valoró las formas tradicionales de vida, el medio

\footnotetext{
${ }^{72}$ Entrevista N ${ }^{\circ} 12$

${ }^{73}$ Entrevista N ${ }^{\circ} 3$.
} 
ambiente saludable, su cosmovisión respecto a la relación armoniosa con la naturaleza, etc.

Lamentablemente en una sociedad en la cual priman más los intereses económicos y los contratos firmados con empresas privadas 0 transnacionales, se deja de lado lo fundamental, la voz de aquellos que quieren ser escuchados reclamando derechos justos, pero muchas veces para lograr ello es necesario el uso de la violencia. Lo cual lo hemos podido vivenciar directa 0 indirectamente en conflictos acontecidos en Lastay, Bagua, Tambogrande, entre otros. Estos procesos vividos, tarde o temprano generan resentimiento social, indiferencia y acciones colectivas violentas.

"Nuestras autoridades solo piensan en sacar beneficios, pero no están pensando en el pueblo que los eligió. Ellos no quisieron respetar nuestra forma de pensar, ni siquiera nos han preguntado si estamos de acuerdo o no con esa planta, ellos tampoco han tenido en cuenta que varias personas vivimos de la chacra $y$ de nuestros animales, que serían afectados. Además nosotros vivimos tranquilos acá, porqué ellos quieren venir a malograr nuestra tranquilidad con nuestras familias y vecinos. Nosotros vivimos felices en nuestras tierras, en nuestras casitas, viendo cómo sale el sol, como sopla el viento, como crecen nuestros cultivos. A ellos quien le molesta, quien va a su casa a querer echar basura."

Los significados que le dan los actores sociales a la "basura son distintos. Mientras que para unos la "basura" puede significar la obtención de beneficios económicos, para otros significa "contaminación, enfermedades y hasta muerte". Una buena forma de comprender el conflicto dentro de ésta esfera sociológica lo plantea G. H. Mead con la teoría del interaccionismo simbólico, refiriéndose a "la capacidad del individuo en asignar significados a su mundo externo para relacionarse con él (...) a un ámbito local específico y a una cultura específica. Las confusiones interpretativas de hechos y sentimientos serían generalmente causas de malas interpretaciones o posibles conflictos, todo esto sin omitir por supuesto los choques culturales que pueden presentarse al encontrarse "sistemas de valores opuestos" o con "grados de diferenciación simbólica"."74

La sociedad peruana, caracterizada por sus grandes diferencias sociales, muestra puntos en desventaja hacia los sectores menos favorecidos. Precisamente Joan Martínez Alier cuando habla del ecologismo popular, hace referencia al valor que los pobres le dan a las cuestiones ambientales, culturales y sociales, más no tanto así a las cuestiones económicas que sí son de interés para gran parte de la clase política que está en el gobierno. Un gobierno que justificándose en un supuesto "uso legítimo de la violencia"75, quiere imponer su voluntad.

\subsection{Factores legales}

En nuestro país existen diversas leyes y normas, que lamentablemente no se respetan. Por ejemplo la ley General del Medio Ambiente 28611 en su Art. 91 dice: "El Estado es responsable de promover y regular el uso sostenible del recurso suelo, buscando prevenir o reducir su pérdida por erosión o contaminación: cualquier actividad económica 0 de servicio debe evitar el uso de suelos agrícolas".

Si consideramos lo manifestado líneas arriba, la construcción de la planta de tratamiento de residuos sólidos en el anexo de Lastay, estaría contraviniendo a la ley, ya que como lo manifestaron los pobladores, Lastay es una zona donde está presente la actividad agrícola y ganadera. Precisamente, considerando la existencia de leyes y que lamentablemente no se estaban respetando, los pobladores indignados, levantaron su voz de protesta. La misma ley en su Art. 98: expresa: "Se insta a la conservación de los ciclos y procesos ecológicos, para prevenir sus alteraciones por actividades antropogénico." La construcción de la planta de tratamiento en mención, afectaría enormemente el ecosistema existente en Lastay y poblados aledaños.

\footnotetext{
${ }^{74}$ MEAD, G. H. (1972) Espíritu, persona y sociedad. Paidós, Buenos Aires, 3.a ed.

${ }^{75}$ WEBER, M. (1977)"Economía y sociedad". Fondo de cultura económica. México.
} 
Asimismo, la ley 26839 en el artículo 3 refiere: "Conservar la diversidad de los ecosistemas, especies y genes; así como mantener los procesos ecológicos esenciales de los que depende la supervivencia de las especies". Lamentablemente existen autoridades a quienes les interesan prioritariamente los rendimientos económicos, pero obvian la biodiversidad, las cosmovisiones diversas existentes en nuestro país y por ende las leyes que respaldan su protección. $Y$ eso es lo que se puede manifestar en diversos proyectos ejecutados y algunos frustrados, que se contuvo gracias a la acción colectiva, tal es el caso de Lastay, Bagua, entre otros, donde hubo pérdidas humanas y materiales que lamentar. Muchas de nuestras autoridades y "personas" esperan el derramamiento de sangre para repensar y actuar. Lo cual va generando resentimiento social y divisionismo en nuestro país.

\subsection{Factores políticos}

En nuestra sociedad, la cuestión política es pan de cada día y existen personas que se valen de las desgracias de otros para ganar protagonismo y beneficios políticos. Mientras que algunos actores se ven favorecidos, otros se ven perjudicados, pero los que pagan los "platos rotos" es el pueblo.

"El alcalde de Concepción, que estuvo programado para la revocatoria, utilizó el descontento de las poblaciones $y$ encabezó como defensor del medio ambiente y logró neutralizar la intención de la revocatoria en contra de su gestión. Del mismo modo el gobierno regional y nacional utilizó como cortina de humo estos hechos para distraer la atención de la población en la región central. El Alcalde Arana en este conflicto aparece como una persona inepta, sin principio de autoridad, que improvisó una obra, sin tener la licencia social y su gestión generó ante la opinión pública como incapaz."76

Como hemos podido analizar, los factores que ocasionan un conflicto socio ambiental son diversos, los cuales van a perjudicar a la sociedad generando consigo impactos lamentables.

\section{Impactos del conflicto "Muerte y sangre corrió en Lastay"}

\footnotetext{
${ }^{76}$ Entrevistado $\mathrm{N}^{\circ} 12$
}

Los impactos que ocasionó el conflicto socio ambiental acontecido en Lastay, por oposición a la construcción de la planta de tratamiento de residuos sólidos son diversos, pero lo más lamentable son las pérdidas humanas. A continuación presentamos una breve descripción de lo acontecido, recurriendo como fuente a un diario local que manifiesta:

"De pronto, la mañana soleada de ayer (16/11/2008) en el paraje Lastay, Quichuay, se vio trágicamente interrumpida por un cruento enfrentamiento entre pobladores de Concepción y trabajadores de la Municipalidad de Huancayo, dejando un saldo preliminar de "dos" muertos y 50 heridos, vehículos y tiendas de campaña fueron incendiados, seguido de una ola de saqueos.

Más de 2 mil 500 pobladores de Concepción, ciegamente opuestos al proyecto Lastay y provistos de objetos contundentes, irrumpieron por los flancos nororiental y noroccidental del terreno donde la municipalidad de Huancayo ha previsto la construcción de su planta de residuos sólidos, arrasando con todo lo que encontraban a su paso.

Al abrirse camino, la enardecida turba tomó el control de la zona, pasando, incluso, por encima de un contingente policial de menos de cien agentes, cuyas fuerzas se vieron reducidas por falta de apoyo humano y logístico, siendo presa fácil de los ataques.

Nada parecía detenerlos. Los enfurecidos pobladores golpearon sin piedad a todo aquel que les hacia frente, causándoles heridas de toda índole. No era para menos, la inferioridad numérica de los agraviados, de no más de un centenar, redujo sus posibilidades de defensa.

Como expresión de victoria, la frenética muchedumbre quemó siete vehículos, entre ellos cuatro del servicio de Serenazgo y una motocicleta. También incendiaron tiendas de campaña y sustrajeron frazadas, menajes, medicinas, entre otros enseres. Incluso, refirieron fuentes de Huancayo, retuvieron (secuestraron) a cuatro servidores 
municipales, entre ellos Verónica Alvarado Casqui (24), a quienes condujeron a la Municipalidad de Concepción. VÍCTIMAS. En un confuso incidente, Doris Mendoza Paredes (46), murió por impacto de bala. Sin embargo, al cierre de esta edición, la familia de Leonel Gaspar (17), informó de su deceso, no obstante, la noticia no ha sido confirmada por las dificultades que ha tenido la Policía para constatar el hecho. Por su parte, la Municipalidad de Huancayo comunicó que hay 31 heridos, de los cuales Samuel Gutiérrez y Néstor Vila se encuentran con pronóstico reservado. Cabe mencionar que entre los heridos hay 15 agentes de la Unidad de Servicios Especiales de la Policía. A su vez, el fiscal de Concepción, Manuel Medina Pérez, resultó seriamente golpeado."

Desde la perspectiva de la psicología social, cuando los individuos actúan en masa, adquieren lo que Le Bon denomina "un alma colectiva"77, pierden su individualidad, se contagian social y emocionalmente, actúan irresponsablemente porque sienten que en masa mantienen su anonimato, es por ello que en algunos casos se cometen crímenes, tal como lo manifiesta $\mathrm{H}$. Arendt cuando se refiere a "la ausencia de conciencia en las masas y de los crimenes que bajo su anonimato pudieran cometer los grupos que renuncian a una conciencia grupal o individual por una mayor que los enaltece y domina"78 viviendo un actuar caracterizado como "fuente ovejuna."

\section{La negociación}

Cuando hablamos de negociación nos referimos al proceso encaminado a resolver problemas en la cual dos 0 más actores sociales examinan sus discrepancias e intentan alcanzar una decisión conjunta sobre lo que les afecta a ambos. Persigue establecer una relación más deseable para ambas partes a través del intercambio, trueque y compromiso de derechos, sean éstos legales, económicos, ecológicos, sociales o psicológicos; siendo su objetivo lograr un orden de relaciones donde antes no lo existían y modificar un conjunto de relaciones sociales

\footnotetext{
77 Freud, Sigmund, (1974) Psicología de las masas. Alianza editorial, Madrid España

${ }^{78}$ ARENDT, H: (1981-1982) Los orígenes del totalitarismo" (versión española de Guillermo Solana), 3 vols. (1. Antisemitismo, 2. Imperialismo, 3. Totalitarismo), Alianza Universidad (Nos 309, 316 y 335), Madrid.
}

existentes por otras más convenientes para una de las partes o para ambas partes. ${ }^{79}$

\subsection{La mediación ¿Negociación frustrada?}

El conflicto acontecido en la frustrada construcción de la planta de tratamiento de residuos sólidos en Lastay, tuvo diversos intentos de negociación, en el cual se recurrió en primera instancia a la negociación asistida, específicamente al método de mediación, en la cual el Arzobispo de Huancayo, Monseñor Pedro R. Barreto Jimeno, cumplió el rol de mediador, entendiendo que la mediación es un método de negociación de conflictos que se caracteriza por ser un "mecanismo en el cual interviene un tercero que ayuda a las partes para arribar a una solución pero sin proponer fórmulas de solución. El papel del tercero es mejorar la comunicación entre las partes para que éstas precisen con claridad el conflicto, descubran sus intereses y generen opciones para hacer realizable un acuerdo satisfactorio." ${ }^{80}$ Lamentablemente las diversas mesas de negociación, no tuvieron resultados favorables, sino que los ánimos de los actores directos del conflicto representado por los alcaldes de Huancayo y Concepción, se tornaban cada vez más violentos, ya que hubo diversas agresiones verbales por parte de los mismos, sin considerar el debido respeto al mediador.

\subsection{Necesidad de Arbitrar el conflicto. Conformación de la Mesa Multisectorial de Alto Nivel}

Considerando que el conflicto en torno a la construcción de la planta de tratamiento de residuos sólidos en Lastay, no llegaba a una solución, hubo necesidad del surgimiento de la Comisión Multisectorial de Alto Nivel, conformada por: el Ministro de Salud, Vice Ministro de Gestión Ambiental, Director General de la División General de Salud Ambiental, Defensoría del Pueblo, representante del Consejo de Ministros y Presidente Regional de Junín, Dr. Vladimiro Huaroc; estuvieron también los Alcaldes de las provincias de Huancayo y Concepción. Según Vladimiro Huaroc, la Comisión de Alto Nivel se conformó con el "objetivo de analizar el expediente que ha desembocado en construir la planta de tratamiento de residuos sólidos", para ver la viabilidad o no de tal proyecto. Asimismo manifestó que "las conclusiones a las que llegue dicha Comisión tendrán que ser respetadas por las

\footnotetext{
${ }^{79}$ Vásquez, R. W. Op. Cit Pg. $10-11$.

${ }^{80}$ Ibid. Pg. 12.
} 
partes." En tal sentido, en esta segunda etapa se considera también la negociación asistida, específicamente el arbitraje, "método de resolver extrajudicialmente controversias, donde el árbitro no propone ni sugiere, sino resuelve y las partes tienen que acatar (...) La voluntad de las partes se somete a la voluntad de un tercero". 81

Considerando el acuerdo de la Comisión de Alto Nivel, el Presidente Regional de Junín, Vladimiro Huaroc, informó que se acordó postergar la construcción de la planta de tratamiento de los residuos sólidos en el anexo de Lastay, distrito de Quichuay; en ese sentido indicó que junto a los municipios de la región se buscará lugares aptos para acumular desechos sólidos del Valle del Mantaro. En los próximos días el pleno del Consejo de Ministros dará a conocer la Resolución de acuerdo al acta firmada por los comisionados en el caso Lastay en referencia a la construcción de la planta de tratamiento de los residuos sólidos. El titular de la Región Junín de acuerdo al acta firmada mencionó que esta construcción no da para más y ya no cumple con los requisitos necesarios. Al respecto Vladimiro Huaroc refiere que "Por razones sociales y también porque ahí la necesidad que la normatividad que rige no solamente en el caso Lastay sino en toda la construcción de plantas de tratamiento no está debidamente normada, no está completo, hay vacíos, es necesario que tanto el Ministerio del Medio Ambiente y DIGESA, elaboren algunos expedientes técnicos que tengan que ver con una norma mucho más estricta para el cumplimiento de estos procesos".

En tal sentido, la acción colectiva, logró la propuesta de una reforma en cuanto a la ley, como lo manifiesta Huaroc Portocarrero "es necesario que tanto el Ministerio del Medio Ambiente y DIGESA, elaboren algunos expedientes técnicos que tengan que ver con una norma mucho más estricta para el cumplimiento de estos procesos". Entonces las acciones colectivas en un conflicto social, tal vez no logren una revolución, es decir el cambio de todo el sistema, pero si logran una reforma, tal como Lewis A. Coser, refiere al respecto: "el conflicto puede conducir vía reforma a cambios dentro del sistema y vía revolución a cambios del sistema." 82

\footnotetext{
81 Ver: Art. 9 de la Ley 26872.

${ }^{82}$ Lewis A C. (1961) Las Funciones del Conflicto Social. Fondo de Cultura Económica, México.
}

Con la conclusión a la que llegó la Comisión de Alto Nivel, se calmaron los ánimos en Lastay, pero el problema respecto a la disposición final de residuos sólidos de Huancayo no concluyó, sino que continúa; la Municipalidad Provincial de Huancayo conjuntamente con la empresa DIESTRA continúan buscando lugares para la construcción de una planta de tratamiento de residuos sólidos, es así que "se puso el ojo" en el barrio de Cajas Chico", pero la población no aceptó, luego en MarcavallePucará, y la población aún no otorga la licencia social para tal construcción. En tal sentido el problema de "la basura" ya no significa sólo problema para la Municipalidad, sino, ya es un problema que acata a la sociedad en su conjunto, porque todos en menor o mayor grado, generamos cantidades de residuos sólidos.

\section{CONCLUSIONES}

- El conflicto socioambiental en el anexo de Lastay fue motivado por la existencia de intereses contrapuestos entre la Municipalidad de Huancayo, anexo de Lastay y, los pueblos de la provincia de Concepción. En este proceso no se ha previsto la sensibilización social como acción previa para lograr la licencia social. La empresa Diestra priorizó la factibilidad técnica y financiera y soslayó la factibilidad social, político, ambiental y cultural.

- Las causas del conflicto socio ambiental del caso Lastay se caracterizó por ser multifactorial, siendo ellos el ambiental, económico, sociocultural, legal y político.

- Los pobladores de los distritos de: Matahuasi (provincia de Concepción), Quichuay, Ingenio, San Jerónimo (de la provincia de Huancayo) encabezados por los líderes y dirigentes vecinales, las organizaciones civiles, frentes de defensa se organizaron con la participación de niños, adultos y ancianos y bloquearon la carretera central Concepción - Huancayo exigiendo detener la construcción de la planta de tratamiento en Lastay. A pesar de esta advertencia el Alcalde Freddy Arana mostrando una actitud terca continúo la construcción.

- Ante esta insistencia de la Empresa Diestra continuar con la construcción, el 17 de noviembre del 2008 con la presencia de más 2500 personas procedentes de los distritos y comunidades campesinas de Casacancha, Álayo, Huaychulo, Ingenio, Concepción, Quichuay, san Jerónimo, Lastay, Santa Rosa de Ocopa, Quilcas, San Pedro de Saño, Santo Domingo, Huanchar, los pobladores de Concepción y Matahuasi invadieron exigiendo dejar sin efecto la construcción de la planta de tratamiento de los residuos sólidos y 
por esta presión social se frustró la continuidad de la construcción. Este hecho evidencia la acción colectiva como expresión de descontento y oposición de la continuidad de la construcción de la planta de tratamiento y como consecuencia fue declarado inviable la continuidad de la obra.

- El conflicto socioambiental del caso Lastay es una demostración de caos social, producto de una acción colectiva de uno de los movimientos sociales que generó crisis política a nivel local, regional con un impacto nacional.

\section{REFERENCIAS BIBLIOGRÁFICAS}

- Ángel, A. La trama de la vida. Bases ecológicas del pensamiento ambiental. Cuadernos Ambientales \# Bogotá: Universidad Nacional IDEA y Ministerio de Educación Nacional. 1993.

- Arendt, H: Los orígenes del totalitarismo" (versión española de Guillermo Solana), 3 vols. (1. Antisemitismo, 2. Imperialismo, 3. Totalitarismo), Alianza Universidad (Nos 309, 316 y 335), Madrid. 1981-1982.

- Ceceña, A. La Guerra por el agua y por la vida. Cochabamba: una experiencia de construcción comunitaria frente al neoliberalismo y al banco mundial. Cochabamba, Bolivia. 2004.

- CIDIAT-GTZ, Cooperación Técnica VenezolanoAlemana. Memorias del Curso Regional sobre Manejo de Conflictos Ambientales. Mérida -Venezuela. 16 al 20 de Septiembre. 2002.

- Comité por la defensa de la vida y el agua. Volante vincúlate a la defensa del río Otún. Pereira. Enero. 2005.

- Corantio Q. Manejo de Conflictos Ambientales. Primera edición. Medellín, Colombia. 2001.

- Crespo F. C. Poder, Dominación y Conflictos: elementos para una crítica de los enfoques de construcción de consensos. CESU UMSS. Cochabamba, Bolivia. 2005.

- Durkheim E. Las reglas del método sociológico. S/E. 1895

- $\quad$ Fontaine G. Enfoques Conceptuales y metodológicos para una sociología de los conflictos ambientales. En: CÁRDENAS, Martha y RODRÍGUEZ, Manuel. Guerra, Sociedad y Medio Ambiente. Foro Nacional Ambiental. Bogotá. 2004.

- $\quad$ FREUD, Sigmund, Psicología de las masas. Alianza editorial, Madrid - España. 1974.

- Garmendia, S. A., Salvador A. A. y otros Evaluación de impacto ambiental, Pearson Prentice Hall, Madrid, España. 2006
- Isaza R. M. y otros. Medio Ambiente y Paz. Asociación Reserva Natural Suma-paz. Corporación Ecofondo. Bogotá. 1998.

- Kurtenbach S. Análisis del Conflicto en Colombia. FES. Bogotá, Colombia. 2005.

- Lewis A. C. Las Funciones del Conflicto Social. Fondo de Cultura Económica, México. 1961.

- Martínez G. A. Métodos Alternativos en Manejo de Conflictos. Aplicaciones en materia ambiental. México: SEMARNAP, PNUD. 1997.

- Marx k. y Engels F. El manifiesto Comunista. 1848

- Mead, G. H. Espíritu, persona y sociedad. Paidós, Buenos Aires, 3.a ed. 1972.

- $\quad$ Novoa J. El conflicto continúa. En: GONZÁLEZ, Juan Manuel y Otros. La Manzana de la Discordia, debate sobre la naturaleza en disputa. Segunda edición. ECOFONDO, Tercer mundo editores S.A. Santafé de Bogotá, Colombia. 1998.

- Oficina Nacional de Procesos Electorales- ONPE, Gerencia de Formación y Capacitación Electoral: módulo de habilidades sociales, ciudadanía y participación. Lima. 2006

- Vásquez, R. W. Manual de medios alternativos de resolución de conflictos. S/E, S/F.

- Vinyamata C. E. Manual de Prevención y Resolución de Conflictos. Conciliación, Mediación, Negociación. Editorial Ariel S.A., Barcelona. 1999.

- Weber, M. "Economía y sociedad". Fondo de cultura económica. México. 1977

- http://es.geocities.com/angelcontrerasna/organizacion/ foro010.htm

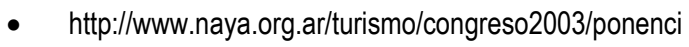
as/Aldo_Ramos2.htm 